\title{
Technical note: Comparison of rectal and vaginal temperatures in lactating dairy cows
}

\author{
L. A. Vickers, ${ }^{*}$ O. Burfeind, $\dagger$ M. A. G. von Keyserlingk, ${ }^{*}$ D. M. Veira, $\ddagger$ D. M. Weary, ${ }^{*}$ and W. Heuwieser ${ }^{*} \dagger^{1}$ \\ ${ }^{*}$ Animal Welfare Program, Faculty of Land and Food Systems, The University of British Columbia, Vancouver, British Columbia, V6T 1Z4, Canada \\ †Sustainable Dairy Reproduction Program, Clinic for Animal Reproduction, Faculty of Veterinary Medicine, Freie Universität, \\ Berlin 14163 Germany \\ $\ddagger$ Agriculture and Agri-Food Canada, Pacific Agriculture Research Station, Agassiz, British Columbia
}

\begin{abstract}
A method commonly used to identify illness in dairy cows is measuring body temperatures with a rectal thermometer, but vaginal measures are becoming common in research. The primary objective of this study was to validate vaginal measures of body temperature by comparing them with rectal temperatures. Data loggers used to collect vaginal temperatures can be programmed to collect many readings per day, providing an opportunity to interpret effects of health in relation to diurnal differences in temperatures. Thus, a secondary objective was to compare the diurnal pattern in body temperatures for cows with and without retained placenta (RP). Body temperature was monitored for $8 \mathrm{~d}$ in 29 cows that had recently calved (enrolled $2 \mathrm{~d}$ after calving; 7 of these cows were diagnosed with RP) and in 13 cows in peak lactation (98 $\pm 8 \mathrm{~d}$ in milk). Rectal temperatures were taken at 0630, 0930, 1230, 1530,1830 , and $2130 \mathrm{~h}( \pm 30 \mathrm{~min})$ with a digital thermometer for $8 \mathrm{~d}$ consecutively. During the same period, vaginal temperatures were measured every $10 \mathrm{~min}$ with a microprocessor-controlled data logger attached to a modified vaginal controlled internal drug release insert. Values from the vaginal loggers were averaged over $1 \mathrm{~h}$ and paired with the corresponding rectal temperature. There was a relationship between rectal and vaginal temperatures for fresh cows $(\mathrm{n}=1,393 ; \mathrm{r}=0.81)$ and for peak-lactation cows $(\mathrm{n}=556 ; \mathrm{r}=0.46)$. Cows with $\mathrm{RP}$ had higher body temperatures $(39.2 \pm 0.01)$ compared with healthy cows $(39.1 \pm 0.01)$. Body temperature was higher at night, and lower between 0800 to 1000 $\mathrm{h}$ for healthy cows $(39.0 \pm 0.02)$ and between 1100 to $1300 \mathrm{~h}$ for RP cows $(39.1 \pm 0.02)$. In summary, vaginal temperatures were associated with rectal measures, and provided the advantage of capturing dirurnal changes in body temperature.
\end{abstract}

Received April 29, 2010.

Accepted July 30, 2010.

${ }^{1}$ Corresponding author: wolfgang.heuwieser@ubc.ca
Key words: postpartum, rectal, temperature, vaginal

Various technologies have been used to continuously monitor body temperature in cattle, including temperature boluses placed in the rumen (Bewley et al., 2008; Ipema et al., 2008), transmitters implanted in the abdominal cavity (Brown-Brandl et al., 2005), thermistors implanted in the udder (Bitman et al., 1984; Lefcourt et al., 1999), and transmitters implanted behind the rib cage (Lefcourt and Adams, 1996). These methods provide useful data, but are invasive. Recently, studies have used microprocessor-controlled data loggers inserted into the vaginal cavity to test the effects of milking frequency (Kendall et al., 2008), low ambient temperatures and wind (Webster et al., 2008), high ambient temperatures (Dikmen et al., 2008), access to shade (Kendall et al., 2006; Tucker et al., 2008; Schütz et al., 2009), and sprinklers (Kendall et al., 2007) on body temperature in cattle. Unfortunately, the temperature loggers used in these studies (Minilog 8, Vemco Ltd., Halifax, Canada) were never validated for this use, and information on the relationship between rectal and vaginal temperatures did not exist. Furthermore, temperature loggers have never been used to continuously monitor body temperature postpartum, the period when dairy cows are most susceptible to disease. The most commonly used method to identify illness in dairy cows is measuring body temperature with a rectal thermometer (Smith and Risco, 2005).

Data loggers facilitate frequent measures of body temperature and provide the opportunity to assess the effects of illness in the context of natural diurnal variations. For almost a century, it has been known that cattle experience diurnal changes in body temperature (e.g., Kriss, 1920; Wrenn et al., 1958), although the timing of peaks and troughs has been debated (Wrenn et al., 1961; Bitman et al., 1984) and these may vary with ambient conditions and animal or breed characteristics (Bewley et al., 2008). Overall, body temperature increases in the afternoon and decreases during the 
early morning hours (Bitman et al., 1984; Kendall et al., 2006).

The primary objective of this study was to validate the application of vaginal loggers to measure body temperature by comparing estimates obtained from the logger with rectal temperatures. A secondary objective was to compare the diurnal pattern in body temperature in healthy cows that recently calved and those diagnosed with retained placenta $(\mathbf{R P})$.

The main in vivo observations were conducted between November 2008 and September 2009 at The University of British Columbia Dairy Education and Research Centre (Agassiz, Canada). Supplementary observations were performed in January 2010 at the Clinic of Animal Reproduction, Freie Universität Berlin (Germany). Cows were managed according to the guidelines set by the Canadian Council on Animal Care (1993) and by the International Cooperation on Harmonisation of Technical Requirements for Registration of Veterinary Medicinal Products (2000), respectively. Forty-two Holstein cows were enrolled.

The study began with an in vitro phase evaluating variation among data loggers and compared values with a calibrated thermometer as a gold standard. Five different temperature loggers (Minilog 8; capable of recording temperatures from 0 to $40.5^{\circ} \mathrm{C}$ ) and a calibrated liquid-in-glass thermometer (validated by the Office of Legal Metrology of the State of Hessen, Germany; Type E 0.1/0/50 DIN 12775; serial number 3636; verification certificate 5-3636-09) were placed into the same water bath (Haake SWB 25, Thermo Electron GmbH, Karlsruhe, Germany). The water bath contained $16 \mathrm{~L}$ of water adjusted to $35^{\circ} \mathrm{C}$. Data loggers were programmed to record the first measurement after an acclimatization phase of $15 \mathrm{~min}$ and at 30-s intervals thereafter. Every $23 \mathrm{~min}$, the temperature of the water bath was increased by $1.0^{\circ} \mathrm{C}$, covering a range from 35.0 to $40.0^{\circ} \mathrm{C}$. For $15 \mathrm{~min}$ after a temperature change, values recorded were discarded to exclude errors due to acclimatization. Thus, a total of 480 (96 per logger) paired measurements could be used for analysis.

During the main in vivo phase, vaginal and rectal body temperatures were measured in 21 multiparous (parity $=3.7 \pm 1.8$ ) and 8 primiparous Holstein dairy cows from 2 to $10 \mathrm{~d}$ postpartum to study the relationship between vaginal and rectal body temperature and to describe diurnal temperature fluctuations. Within 24 $\mathrm{h}$ after parturition, cows were moved to postpartum group pens, each containing 12 freestalls fitted with mattresses (Pasture Mat, Promat Inc., Woodstock, Ontario, Canada) covered with $5 \mathrm{~cm}$ of sand bedding, 6 Insentec feed bins (Insentec, Marknesse, Holland), and 1 Insentec water trough. Stocking density was maintained at 12 animals per pen. Group composition was dynamic, with cows entering and leaving the experiment depending on their calving dates. Cows were fed a TMR consisting of $39.7 \%$ concentrate and mineral mix, $32.9 \%$ grass silage, $19.2 \%$ corn silage and $8.2 \%$ alfalfa $\left(\mathrm{NE}_{\mathrm{L}}=1.65 \mathrm{Mcal} / \mathrm{kg}\right)$. Postpartum cows were milked (at approximately 0800 and $1800 \mathrm{~h}$ ) and fed (at approximately 0600 and $1600 \mathrm{~h}$ ) twice daily. Peaklactation cows also were milked (at approximately 0500 and $1700 \mathrm{~h}$ ) and fed (at approximately 0530 and 1530 h) twice daily.

A case of RP was diagnosed if the fetal membranes were observed to be suspended from the vulva $24 \mathrm{~h}$ after calving. Of the 21 multiparous cows enrolled, 7 (parity $=4.6 \pm 2.0$ ) were diagnosed with RP either alone or in combination with concomitant diseases such as mastitis $(\mathrm{n}=1)$, metritis $(\mathrm{n}=1)$, ketosis $(\mathrm{n}=1)$, milk fever $(\mathrm{n}=1)$, and respiratory issues $(\mathrm{n}=2)$. All primiparous cows expelled the placenta within $24 \mathrm{~h}$ of calving. Multiparous cows with RP were match-paired with the next multiparous cow that calved, had shed the placenta within $24 \mathrm{~h}$, and did not demonstrate clinical signs of disease during daily health examinations (parity $=4.4 \pm 2.4)$. Cows with $\mathrm{RP}$ received a systemic antibiotic treatment consisting of 7.5 million IU of penicillin G (Procillin, Bimeda-MTC Animal Health, Cambridge, Ontario, Canada) applied subcutaneously for $3 \mathrm{~d}$ consecutively, according to standard operating procedures on the farm.

Vaginal and rectal temperatures were monitored in 13 peak-lactation cows (DIM $=98 \pm 8$; parity $2.2 \pm$ 1.5) for $8 \mathrm{~d}$ consecutively in a second experiment. These cows were housed in a freestall barn with access to deep-bedded sand stalls and had free access to feed and water. All cows were healthy throughout the observation period.

For both the postpartum and peak-lactation cows, rectal temperatures were measured daily at 0630, 0930, $1230,1530,1830,2130 \mathrm{~h}( \pm 30 \mathrm{~min})$ with a digital thermometer (GLA M750, GLA Agricultural Electronics, San Luis Obispo, CA, or KD 2110, SES Scala Electronics, Stahnsdorf, Germany). For postpartum and peak-lactation cows, 50 (on d 2 at 1830 and $2130 \mathrm{~h}$ and 6 times/d for $8 \mathrm{~d})$ and $48(6 \times 8 \mathrm{~d})$ measures were conducted, respectively. Vaginal temperatures were measured at 10-min intervals with a microprocessorcontrolled temperature logger from the in vitro portion. Data loggers $($ size $=92 \mathrm{~mm} \times 20 \mathrm{~mm}$; weight $=40.5$ $\mathrm{g})$ were inserted in the vaginal cavity using a modified vaginal controlled internal drug release insert.

Ambient temperature ( $\mathbf{T}$, measured in $\left.{ }^{\circ} \mathrm{C}\right)$ and relative humidity $(\mathbf{R H})$ were recorded hourly using HOBO Pro V2 loggers (Onset, Pocasset, MA) secured to wooden beams approximately $3 \mathrm{~m}$ from the ground within the experimental pen. The temperature-humidity 
Table 1. Correlation and differences of paired measurements between digital thermometers inserted into the rectum and temperature loggers inserted into the vagina of multiparous Holstein cows

\begin{tabular}{|c|c|c|c|c|c|c|c|}
\hline \multirow[b]{2}{*}{ Category } & \multirow{2}{*}{$\begin{array}{l}\text { Observation } \\
\text { period (DIM) }\end{array}$} & \multirow{2}{*}{$\begin{array}{c}\text { Paired } \\
\text { observations }\end{array}$} & \multicolumn{2}{|c|}{$\begin{array}{l}\text { Coefficient of } \\
\text { correlation }\end{array}$} & \multicolumn{3}{|c|}{ Differences of paired measurements } \\
\hline & & & $\mathrm{r}$ & $P$-value & Mean $\pm \mathrm{SD}\left({ }^{\circ} \mathrm{C}\right)$ & Paired $t$ & $P$-value \\
\hline Healthy postpartum cows $(\mathrm{n}=7)$ & $2-10$ & 292 & 0.75 & $<0.001$ & $0.0 \pm 0.1$ & 5.39 & $<0.001$ \\
\hline $\begin{array}{l}\text { Postpartum cows with retained } \\
\text { placenta }(\mathrm{n}=7)\end{array}$ & $2-10$ & 333 & 0.75 & $<0.001$ & $0.0 \pm 0.1$ & 4.55 & $<0.001$ \\
\hline Postpartum cows total $(\mathrm{n}=29)$ & $2-10$ & 1,393 & 0.81 & $<0.001$ & $0.0 \pm 0.0$ & 2.39 & $<0.05$ \\
\hline
\end{tabular}

index (THI) was calculated according to the equation reported by Kendall et al. $(2008)$ : THI $=(1.8 \times \mathrm{T}+$ $32)-[(0.55-0.0055 \times \mathrm{RH}) \times(1.8 \times \mathrm{T}-26)]$.

Some of the differences in records from the vaginal loggers and rectal readings could relate to variation in body temperature within each hour. Thus, a supplemental in vivo phase was designed to provide paired readings from the 2 devices synchronized to the nearest minute. This last phase followed 4 healthy, pregnant cows (156 $\pm 79 \mathrm{~d}$ pregnant). Rectal temperature was measured manually every $30 \mathrm{~min}$ with a digital thermometer (SC 112, SES Scala Electronics; probe length $=11.5 \mathrm{~cm}$ ) over a period of $12.5 \mathrm{~h}$, providing 25 measures per cow. Temperature loggers were inserted into the vaginal cavity and programmed to record the temperature every minute. The exact time of the rectal temperature measurement was recorded and the value was compared with the vaginal temperature recorded by the logger at the same minute.

Data were screened for normality using Proc Univariate (SAS Institute, 2003), and extreme outliers $(\mathrm{n}=6)$ were removed. Values from loggers inserted into cows that were below $37.4^{\circ} \mathrm{C}$ (i.e., measurements confounded by ambient temperature due to logger movement) were considered artifacts and excluded from analysis. Data from the vaginal loggers were averaged by 1 -h period and paired with the corresponding rectal temperature. The relationship between rectal temperature (independent variable) and the measurement from the vaginal logger (dependent variable) was assessed using Pearson correlation (SAS Institute, 2003), analyzed separately for postpartum and peak-lactation cows. Vaginal temperatures were correlated with $\mathrm{T}$, using hourly averages (SAS Institute, 2003). Differences between healthy postpartum cows and postpartum cows with RP, and healthy postpartum cows and peak-lactation cows, were tested using paired $t$-tests.

In the in vitro portion of experiment 1, 480 paired observations could be used to validate the temperature loggers. The mean difference between the values recorded by the temperature loggers and the water bath was low $\left(0.1^{\circ} \mathrm{C} \pm 0.1^{\circ} \mathrm{C}\right)$. Also, a relationship was observed between the temperature of the water bath and the recorded temperature of the loggers $(\mathrm{r}=0.99$; $P<0.001)$. Differences between loggers were small (CV $=0.005)$.

A total of 11 cows (4 postpartum cows, 7 peak-lactation cows) had some unusable data due to logger failure. From the original data set generated in vivo, $3.5 \%$ and $10.9 \%$ of paired observations were removed because of logger failure or low temperature values $\left(<37.4^{\circ} \mathrm{C}\right)$ for postpartum cows and peak-lactation cows, respectively. In postpartum cows, loggers were inserted $2 \mathrm{~d}$ postpartum. At this time, the vaginal cavity was enlarged due to calving. Therefore, it was assumed that there was a risk of logger movement resulting in the sensor end pointing to the external environment. In 7 peak-lactation cows, loggers were pushed out of the vagina and reinserted after different time periods, accounting for 277 unusable observations (2.0\%). A similar percentage of unusable data due to logger failure $(6.6 \%)$ was reported using the same type of temperature logger (Tucker et al., 2008). In 24 observations, rectal recordings exceeded the maximum temperature that the vaginal loggers were able to record $\left(40.5^{\circ} \mathrm{C}\right)$; these observations $(1.7 \%$ of the total sample) were also excluded from our analysis.

Daily $\mathrm{T}$ (mean $\pm \mathrm{SD}$ ) was $7.1^{\circ} \mathrm{C} \pm 3.9^{\circ} \mathrm{C}$ during the main in vivo study. No relationships were observed between THI recorded during the 2 experiments (postpartum cows: $49.0 \pm 4.5$; peak-lactation cows: $51.9 \pm$ 4.8) and rectal $(\mathrm{r}=0.14, P<0.001 ; \mathrm{r}=0.1, P<0.001)$ or vaginal temperatures $(\mathrm{r}=0.26, P<0.001 ; \mathrm{r}=0.22$, $P<0.001$ ), respectively. The absence of an association between $\mathrm{T}$ and body temperature may be indicative of relatively moderate environmental conditions compared with other studies conducted in tropical climates (Kendall et al., 2006).

After exclusion of unusable data due to logger failure, 1,393 and 556 paired observations were used to evaluate correlations between rectal and vaginal temperatures for postpartum and peak-lactation cows, respectively. Correlation coefficients (r) between vaginal and rectal measures were $\mathrm{r}=0.81$ for postpartum cows $(P<$ 0.001 ; Table 1) and $\mathrm{r}=0.46$ for peak-lactation cows 


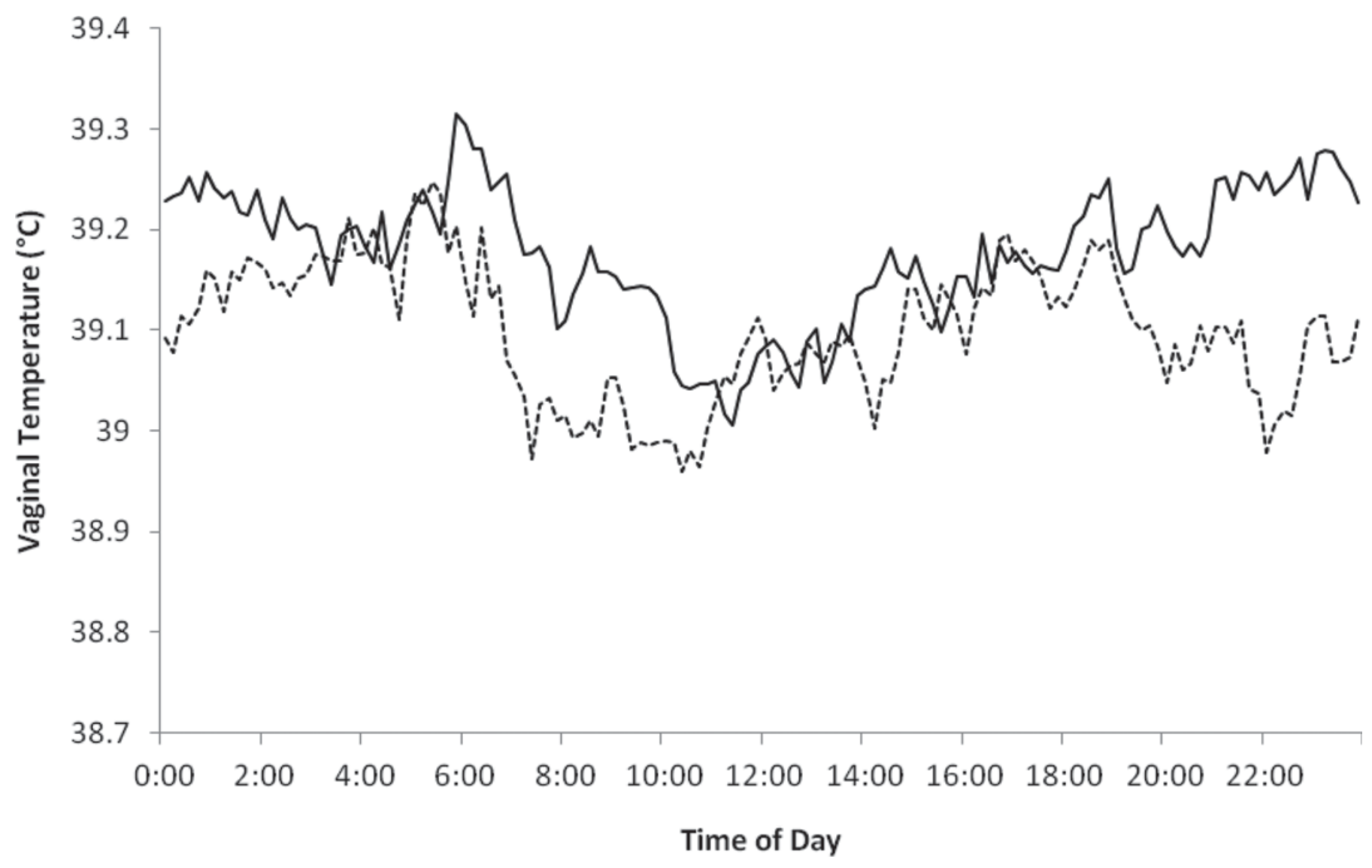

Figure 1. Body temperature rhythms for multiparous postpartum cows with $(-; \mathrm{n}=7)$ and without $(----; \mathrm{n}=7)$ retained placenta.

$(P<0.001)$. Coefficients of correlation in this data set were higher than those reported for the reticulum and rectum $(\mathrm{r}=0.65)$ by Bewley et al. (2008), who reported a relationship for ill and postpartum cows $(\mathrm{r}=$ $0.76)$ compared with later lactation cows $(\mathrm{r}=0.57)$. In both cases, the relationship between rectal and vaginal temperatures in postpartum cows may be due to the greater temperature range exhibited by postpartum cows $\left(37.7\right.$ to $\left.40.5^{\circ} \mathrm{C}\right)$ compared with peak-lactation cows $\left(37.9\right.$ to $\left.39.6^{\circ} \mathrm{C}\right)$.

When comparing a standard with a new method, it is important to recognize that neither approach may be ideal. For example, rectal measures are limited by intra-observer variability, penetration depth, and thermometer type (Burfeind et al., 2010). Vaginal measures are likely affected by logger movement and influx of outside air, particularly when the cow is lying down. In addition, the accuracy of commercially available electronic thermometers is usually $\pm 0.1^{\circ} \mathrm{C}$, but for the temperature loggers, it is $\pm 0.3^{\circ} \mathrm{C}$. As a result, any comparison of 2 methods will reflect errors in both approaches.
During the main in vivo component of the study, rectal temperatures were measured at preset times with a variation of $\pm 30 \mathrm{~min}$. The supplementary in vivo component was added to determine if the relationship between rectal and vaginal measures could be improved by using measures that were paired more precisely in time. Not surprisingly, the coefficient of correlation was found to be higher $(\mathrm{r}=0.85, P<0.001)$ when the 2 measurements were separated by less than $10 \mathrm{~min}$; increasing time intervals were less related $(20$ min: $\mathrm{r}=0.81, P<$ 0.001; 40 min: $\mathrm{r}=0.72, P<0.001)$. These data indicate that a portion of the variance in the main in vivo component was due to differences in the exact times of the 2 temperature-recording methods. The exact time of the rectal temperature measurement was not recorded in the main in vivo experiment. It is possible that timing of the rectal temperature measurement was more precise for postpartum cows compared with peak-lactation cows. This could explain the lower correlation between rectal and vaginal measures in peak-lactation cows.

The body temperature rhythms of multiparous cows with RP were similar to those of healthy multiparous 


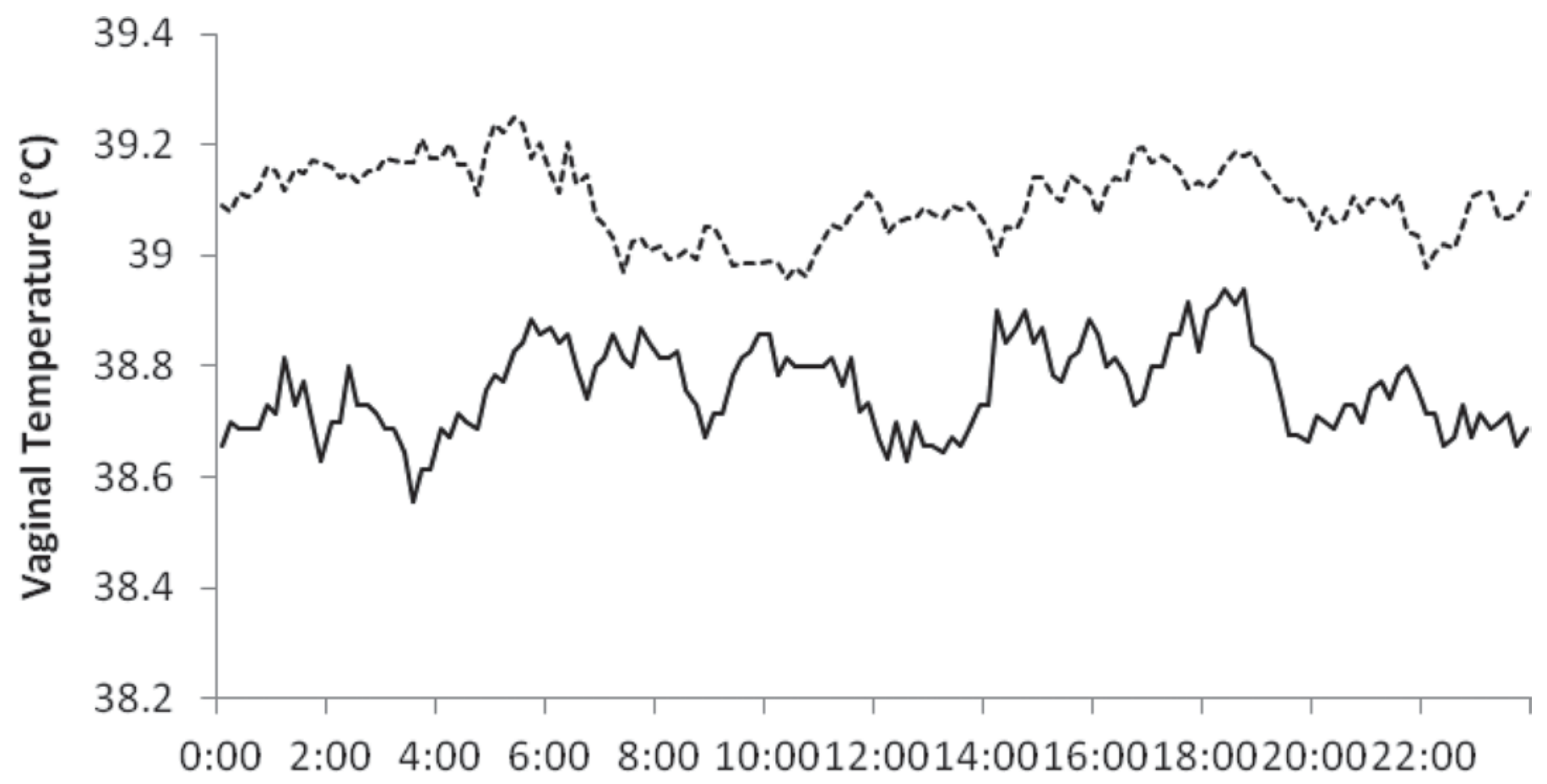

\section{Time of Day}

Figure 2. Body temperature rhythms for peak-lactation cows $(-; \mathrm{n}=13)$ and postpartum cows $(----; \mathrm{n}=21)$.

and primiparous cows (Figure 1). Highest temperatures for cows with $\mathrm{RP}\left(39.3 \pm 0.5^{\circ} \mathrm{C}\right)$ were observed in the early morning (around $0600 \mathrm{~h}$ ), whereas the lowest values $\left(39.0 \pm 0.5^{\circ} \mathrm{C}\right)$ were observed between morning and midday (around 0800 to $1300 \mathrm{~h}$ ). Mean body temperature of RP cows averaged $0.1^{\circ} \mathrm{C}$ higher than matched control cows that were healthy $(P<0.001)$. The diurnal rhythm observed was consistent with earlier reports for cows later in lactation (Bitman et al., 1984). Several factors influenced the time of daily maximum and minimum $\mathrm{T}$, such as ambient conditions, housing, and season (Kendall et al., 2006; Webster et al., 2008; Schütz, 2009).

A diurnal temperature rhythm was evident for peaklactation cows as has been described elsewhere (Bitman et al., 1984; Ipema et al., 2008; Webster et al., 2008; Figure 2). This rhythm consisted of a diphasic temperature pattern (2 peaks and nadirs) over $24 \mathrm{~h}$ (Wrenn et al., 1961); body temperature averaged $0.5^{\circ} \mathrm{C}$ lower in peak-lactation cows compared with postpartum cows.

All 21 postpartum cows reached a temperature above $39.5^{\circ} \mathrm{C}$, commonly used as a threshold indicative of fever, at some point during the 8-d observation period. The highest rectal temperature recorded for postpartum cows was $41.4^{\circ} \mathrm{C}$. Only 3 cows in peak lactation reached temperatures above $39.5^{\circ} \mathrm{C}$, and then only for a maximum duration of $10 \mathrm{~min}$. Comparisons of postpartum and peak-lactation cows should be regarded with caution as these experiments were not conducted simultaneously, but THI for postpartum cows (49.0 \pm $4.5)$ and peak-lactation cows $(51.9 \pm 4.8)$ were similar. Higher temperatures for postpartum cows, especially those with RP, may be associated with the presence of bacteria in the uterus following parturition (Dohmen et al., 2000). Escherichia coli were present in the uterus of $97 \%$ of cows with RP and $33 \%$ of healthy cows 1 to $2 \mathrm{~d}$ after parturition. However, RP cows were previously infected with various other bacteria in addition to E. coli, such as Clostridium spp. and anaerobes, likely favoring uterine infections (Dohmen et al., 2000). The minor increase in mean body temperature of cows with RP may be due to the rapid antibiotic treatment that reduced the prevalence of acute metritis (Risco and Hernandez, 2003; Drillich et al., 2006).

Although vaginal loggers have been used in livestock research for years, to our knowledge, this is the first validation of the system. The readings from the vaginal loggers were closely matched with those from a calibrated liquid-in-glass thermometer in a water bath (gold standard) and with rectal temperatures as the cow-side reference method. The data provide evidence that vaginal loggers can provide a reasonable measure 
of body temperature. The strength of the relationship between vaginal and rectal temperature depends on the temperature range and the time difference between the measures. Healthy cows and those at risk for disease (with RP) both showed a diurnal temperature rhythm, suggesting that clinicians and researchers should be cautious about placing much weight on a single measure of body temperature.

\section{REFERENCES}

Bewley, J. M., M. E. Einstein, M. W. Grott, and M. M. Schutz. 2008. Comparison of reticular and rectal core body temperatures in lactating dairy cows. J. Dairy Sci. 91:4661-4672.

Bitman, J., A. Lefcourt, D. L. Wood, and B. Stroud. 1984. Circadian and ultradian temperature rhythms of lactating dairy cows. J. Dairy Sci. 67:1014-1023.

Brown-Brandl, T. M., R. A. Eigenberg, J. A. Nienaber, and G. L. Hahn. 2005. Dynamic response indicators of heat stress in shaded and non-shaded feedlot cattle, part 1: Analyses of indicators. Biosystems Eng. 90:451-462.

Burfeind, O., M. A. G. von Keyserlingk, D. M. Weary, D. M. Veira, and W. Heuwieser. 2010. Short communication: Repeatability of rectal temperature in dairy cows. J. Dairy Sci. 93:624-627.

Canadian Council on Animal Care. 1993. Guide to the Care and Use of Experimental Animals. Vol. 1. E. D. Olfert, B. M. Cross, and A. A. McWilliam, ed. CCAC, Ottawa, Ontario, Canada.

Dikmen, S., E. Alava, E. Pontes, J. M. Fear, B. Y. Dikmen, and T. A. Olson. 2008. Differences in thermoregulatory ability between slickhaired and wild-type lactating Holstein cows in response to acute heat stress. J. Dairy Sci. 91:3395-3402.

Dohmen, M. J. W., K. Joop, A. Sturk, P. E. J. Bols, and J. A. C. M. Lohuis. 2000. Relationship between intra-uterine bacterial contamination, endotoxin levels and the development of endometritis in postpartum cows with dystocia or retained placenta. Theriogenology 54:1019-1032.

Drillich, M., U. Reichert, M. Mahlstedt, and W. Heuwieser. 2006. Comparison of two strategies for a systemic antibiotic treatment of dairy cows with retained fetal membranes: preventive vs. selective treatment. J. Dairy Sci. 89:1502-1508.

International Cooperation on Harmonisation of Technical Requirements for Registration of Veterinary Medicinal Products. 2000. K. Hellmann, and I. Radeloff, ed. VICH, Brussels, Belgium.

Ipema, A. H., D. Goense, P. H. Hogewerf, H. W. J. Houwers, and H. van Roest. 2008. Pilot study to monitor body temperature of dairy cows with a rumen bolus. Comput. Electron. Agric. 68:49-52.
Kendall, P. E., P. P. Nielsen, J. R. Webster, G. A. Verkerk, R. P. Littlejohn, and L. R. Matthews. 2006. The effects of providing shade to lactating dairy cows in a temperate climate. Livest. Sci. 103:148-157.

Kendall, P. E., C. B. Tucker, D. E. Dalley, D. A. Clark, and J. R. Webster. 2008. Milking frequency affects the circadian body temperature rhythm in dairy cows. Livest. Sci. 117:130-138.

Kendall, P. E., G. A. Verkerk, J. R. Webster, and C. B. Tucker. 2007. Sprinklers and shade cool cows and reduce insect-avoidance behavior in pasture-based dairy systems. J. Dairy Sci. 90:3671-3680.

Kriss, M. 1920. Observations on the body temperature of dry cows. Proc. Natl. Acad. Sci. USA 6:539-541.

Lefcourt, A. M., and W. R. Adams. 1996. Radiotelemetry measurement of body temperatures of feedlot steers during summer. J. Anim. Sci. 74:2633-2640.

Lefcourt, A. M., J. B. Huntington, R. M. Akers, D. L. Wood, and J. Bitman. 1999. Circadian and ultradian rhythms of body temperature and peripheral concentrations of insulin and nitrogen in lactating dairy cows. Domest. Anim. Endocrinol. 16:41-55.

Risco, C. A., and J. Hernandez. 2003. Comparison of ceftiofur hydrochloride and estradiol cypionate for metritis prevention and reproductive performance in dairy cows affected with retained fetal membranes. Theriogenology 60:47-58.

SAS Institute. 2003. SAS User's Guide. Version 9.1. SAS Institute Inc., Cary, NC.

Schütz, K. E., A. R. Rogers, N. R. Cox, and C. B. Tucker. 2009. Dairy cows prefer shade that offers greater protection against solar radiation in summer: Shade use, behaviour, and body temperature. Appl. Anim. Behav. Sci. 116:28-34.

Smith, B. I., and C. A. Risco. 2005. Management of periparturient disorders in dairy cattle. Vet. Clin. North Am. Food Anim. Pract. $21: 503-521$.

Tucker, C. B., A. R. Rogers, and K. E. Schütz. 2008. Effect of solar radiation on dairy cattle behaviour, use of shade and body temperature in a pasture-based system. Appl. Anim. Behav. Sci. 109:141-154.

Webster, J. R., M. Stewart, A. R. Rogers, and G. A. Verkerk. 2008. Assessment of welfare from physiological and behavioural responses of New Zealand dairy cows exposed to cold and wet conditions. Anim. Welf. 17:19-26.

Wrenn, T. R., J. Bitman, and J. F. Sykes. 1958. Body temperature variations in dairy cattle during the estrous cycle and pregnancy. J. Dairy Sci. 41:1071-1076.

Wrenn, T. R., J. Bitman, and J. F. Sykes. 1961. Diurnal patterns of bovine body temperature. J. Dairy Sci. 44:2077-2080. 